\title{
Silicon Dioxide in Mineralized Heart Valves
}

\author{
A. Titov ${ }^{1,2(\bowtie)}$, V. Zaikovskii ${ }^{1}$, and P. M. Larionov ${ }^{1,3}$ \\ ${ }^{1}$ National Research University, Novosibirsk, Russia \\ titov@igm.nsc.ru \\ ${ }^{2}$ Sobolev V.S. Institute of Geology and Mineralogy of SB RAS, \\ Novosibirsk, Russia \\ ${ }^{3}$ Boreskov Institute of Catalysis of SB RAS, Novosibirsk, Russia
}

\begin{abstract}
This study showed that silicon dioxide of plant origin penetrated into the human body unchanged and was transferred through the blood to the heart, where absorbed by the pathological hydroxyapatite of mineralized heart valves.
\end{abstract}

Keywords: Silicon dioxide $\cdot$ Scanning and transmission electron microscopy • Mineralized heart valves $\cdot$ Bioavailability

\section{Introduction}

Over the past decades, numerous studies have shown that $\mathrm{Si}$ is an essential element and it affects human health. Silicon is present in the body as a trace element, but so far its biochemical function has not been confirmed by experimental data. Bioavailable silicon usually enters the body from solutions. Most easily it diffuses through the membranes and penetrates into the circulatory system in the form of orthosilicate acid, which is present in water, beer and some beverages. Among food products, the most significant sources of silicon are the products of plant origin: wheat, rice, oats, and barley. Despite the fact that vegetable food has a high content of silicon, its bioavailability is very limited due to the poor solubility of the forms of silicon present in the plants (Farooq 2015).

In this paper we present amorphous silica found in the composition of pathological formations - calcified heart valves. To explain the possible route of ingestion of amorphous silica, we considered one of the most common food crops for silicon consumption - rice.

\section{Methods and Approaches}

We studied intraoperative material, which included mineralized aortic and mitral valves of the heart, obtained from patients with acquired heart defects of rheumatic and septic genesis (Titov et al. 2016). Siliceous formations found in the calcifications of the heart valves were compared with the siliceous formations of plant origin: rice straw and husk.

The inventory of methods for structural and elemental analyses included highresolution transmission electron microscopy (HR TEM), scanning electron microscopy (SEM), electron diffraction, and energy-dispersive X-ray spectroscopy (EDX). Electron microscopy was performed using a JEM2010 transmission electron microscope 
(acceleration voltage $200 \mathrm{kV}$, resolution $1.4 \AA$ ) equipped with an EDAX EDS detector (spectral resolution $130 \mathrm{eV}$ ) and a TESCAN MIRA3 scanning electron microscope with an Oxford EDS detector (resolution $128 \mathrm{eV}$ ) and built-in INKA ENERGY software.

\section{Results and Discussion}

Our investigation relied on the data obtained in the studies of the calcified formations on heart valves and their bioprostheses (Titov et al. 2016). The presence of silicon at the trace level was observed in the EDS analyzes of calcified heart valves. The studies of the dispersed material of heart valve calcifications by means of transmission electron microscopy revealed amorphous particles of rounded shape about $100 \mathrm{~nm}$ in diameter, along with hydroxyapatite nanocrystals (Fig. 1). The EDS spectra of these amorphous particles revealed $\mathrm{Si}, \mathrm{O}$, and $\mathrm{C}$ (carbon deposition), which corresponded to silicon dioxide (Fig. 1).

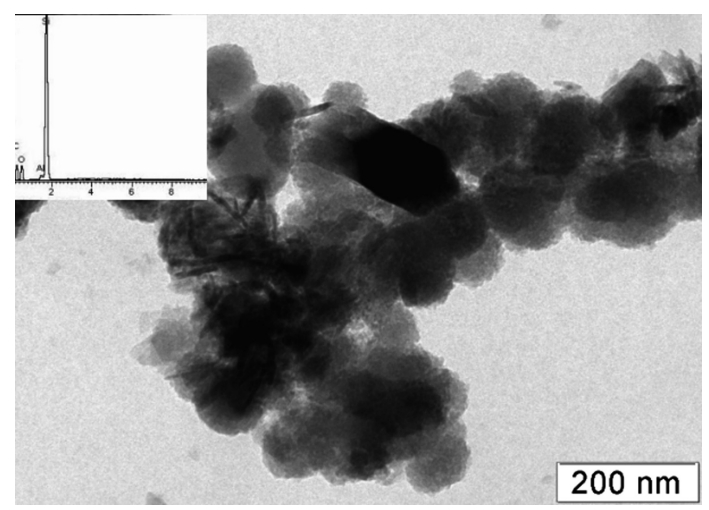

Fig. 1. Electron microscopic image (TEM) of amorphous silica particles among the dispersed calcified mineralized substance of a heart valve. Insert: EDX spectrum from one of the particles of silicon dioxide

As can be seen on the SEM images and EDS spectra of rice straw and husk (Fig. 2.), their surfaces were covered with a thin layer of silicon dioxide. After annealing the rice straw and husk at a temperature of $750{ }^{\circ} \mathrm{C}$, white silica powder remained. The examination of the powder preparation by means of transmission electron microscopy showed that the rice substrate was represented by the rounded particles of amorphous silica with a diameter of about $50 \mathrm{~nm}$ (Fig. 3). The similarity of the amorphous particles of the rice substrate with the amorphous particles from heart valve calcifications in chemical composition and structure seemed quite obvious to us. 


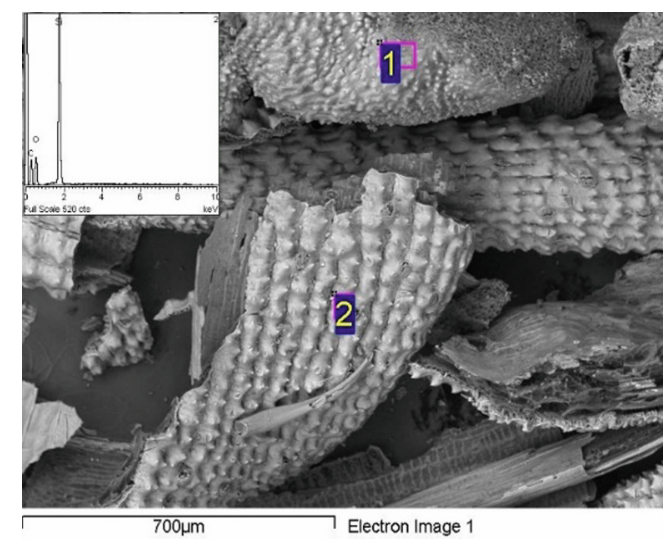

Fig. 2. SEM morphology of rice straw and husk. On the insert is the EDX spectrum from area 2 in the image.

Plants accumulate Si in the form of biogenic (phytolytic) silicon dioxide from soil solutions. It becomes included in plant tissues as a structural component imparting strength and rigidity to the stems. The main route of silicon intake into the organism starts from the gastrointestinal tract. Phytolytic silica is considered to be an insoluble form of Si.

However, most of Si is absorbed from solid products, therefore it is assumed that the phytolytic silicon dioxide is destroyed and absorbed (Jugdaohsingh 2007). Silicon dioxide detected by us in calcifications with nanocrystalline hydroxyapatite, remained unchanged. Apparently silica particles were transferred to the heart valves from the patients' blood and precipitated on hydroxyapatite. Hydroxyapatite is known to have a high sorption capacity (Titov et al. 2013). Perhaps a significant amount of silica can be deposited on the bone tissue as hydroxyapatite is one of its components. Our analysis of the chemical composition of calcified mineralized heart valves using an EDS spectrometer detected silicon at a trace level. The Si content in calcifications is quite significant for this trace element considering the sensitivity level of this method as $0 . n$ weight percent.
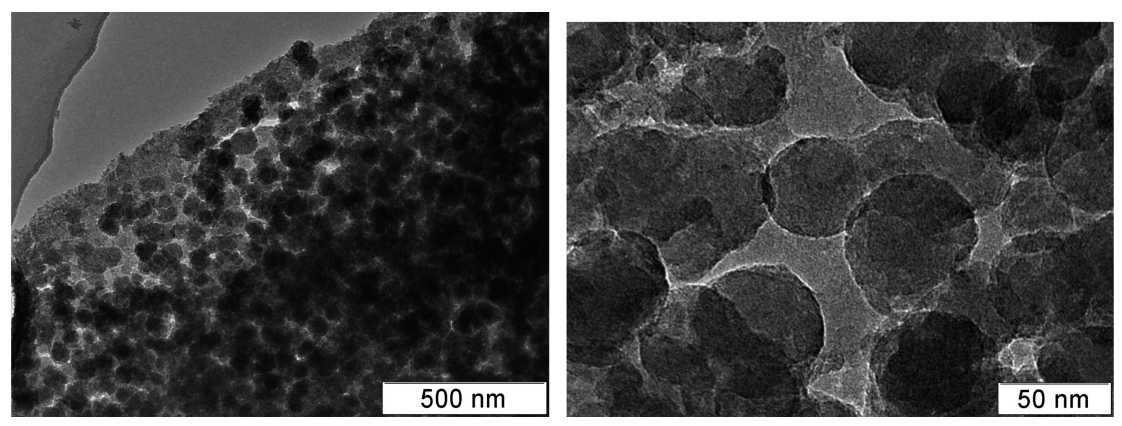

Fig. 3. A and B.Electron microscopic images (TEM) of cytolytic silica obtained from rice straw and husk after annealing at a temperature of $750{ }^{\circ} \mathrm{C}$. B - the image of a fragment of A. 


\section{Conclusions}

To conclude, we suggest that dispersed phytolytic silica may penetrate through the gastric tract into human blood in the unchanged form.

Acknowledgements. This research was carried out within the State Assignment to IGM SB RAS (project 0330-2016-0013).

\section{References}

Farooq MA, Dietz K-J (2015) Silicon as versatile player in plant and human biology: overlooked and poorly understood. Front Plant Sci 6:994-1023

Titov AT, Zaikovskii VI, Larionov PM (2016) Bone-like hydroxyapatite formation in human blood. Int J Environ Sci Educ 11(10):3971-3984

Jugdaohsingh R (2007) Silicon and bone health. J Nutr Health Aging 11(2):99-110

Titov AT, Larionov PM, Zaikovskii I (2013) Calcium phosphate mineralization of bacteria. In: Proceedings of the 11th International Congress For Applied Mineralogy (ICAM), pp 9-17

Open Access This chapter is licensed under the terms of the Creative Commons Attribution 4.0 International License (http://creativecommons.org/licenses/by/4.0/), which permits use, sharing, adaptation, distribution and reproduction in any medium or format, as long as you give appropriate credit to the original author(s) and the source, provide a link to the Creative Commons license and indicate if changes were made.

The images or other third party material in this chapter are included in the chapter's Creative Commons license, unless indicated otherwise in a credit line to the material. If material is not included in the chapter's Creative Commons license and your intended use is not permitted by statutory regulation or exceeds the permitted use, you will need to obtain permission directly from the copyright holder.

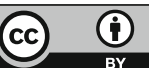

